\title{
Fertility and early pregnancy outcomes after treatment for cervical intraepithelial neoplasia: systematic review and meta-analysis
}

\begin{abstract}
Objective To determine the impact of cervical excision for cervical intraepithelial neoplasia on fertility and early pregnancy outcomes.

Design Systematic review and meta-analysis of cohort studies.

Data sources Medline and Embase.

Eligibility criteria Studies assessing fertility and early pregnancy outcomes in women with a history of treatment for cervical intraepithelial neoplasia versus untreated women. We classified the included studies according to treatment type and fertility or early pregnancy endpoint.

Analysis Pooled relative risks and $95 \%$ confidence intervals using a random effect model, and interstudy heterogeneity with $I^{2}$ statistics.

Results 15 studies fulfilled the inclusion criteria and were included. The meta-analysis did not provide any evidence that treatment for cervical intraepithelial neoplasia adversely affected the chances of conception. The overall pregnancy rate was higher for treated women than for untreated women (four studies; $43 \% v 38 \%$, pooled relative risk 1.29 , 95\% confidence interval 1.02 to 1.64 ), although the heterogeneity between studies was high $(\mathrm{P}<0.0001)$. Pregnancy rates did not differ between women with an intention to conceive (two studies; $88 \% \mathrm{v} 95 \%$, $0.93,0.80$ to 1.08 ) and the number requiring more than 12 months to conceive (three studies, $15 \% v 9 \%, 1.45,0.89$ to 2.37 ). Although the rates for total miscarriages ( 10 studies; $4.6 \%$ v2.8\%, $1.04,0.90$ to 1.21 ) and miscarriage in the first trimester (four studies; $9.8 \% v 8.4 \%, 1.16$, 0.80 to 1.69 ) was similar for treated and untreated women, cervical
\end{abstract}

treatment was associated with a significantly increased risk of miscarriage in the second trimester. The rate was higher for treated women than for untreated women (eight studies; 1.6\% v 0.4\%, 16558 women; 2.60, 1.45 to 4.67$)$. The number of ectopic pregnancies ( $1.6 \% \vee 0.8 \% ; 1.89$, 1.50 to 2.39$)$ and terminations ( $12.2 \% \vee 7.4 \% ; 1.71,1.31$ to 2.22$)$ was also higher for treated women.

Conclusion There is no evidence suggesting that treatment for cervical intraepithelial neoplasia adversely affects fertility, although treatment was associated with a significantly increased risk of miscarriages in the second trimester. Research should explore mechanisms that may explain this increase in risk and stratify the impact that treatment may have on fertility and early pregnancy outcomes by the size of excision and treatment method used.

\section{Introduction}

Cervical screening for the early identification and treatment of cervical intraepithelial neoplasia has reduced the incidence and mortality from cervical cancer. ${ }^{1}$ As the precancerous lesions and their treatment typically occur in women of reproductive age, the impact of conisation on the outcomes of subsequent pregnancies has been an area of active research for the past decade.

Meta-analyses ${ }^{23}$ and large retrospective linkage studies ${ }^{45}$ suggest that the excisional methods of treatment (cold knife conisation, large loop excision of the transformation zone (LLETZ), and 
laser conisation) increase the risk of preterm birth, low birth weight, premature rupture of membranes, and perinatal mortality in subsequent pregnancies; cervical intraepithelial neoplasia itself and other confounders may contribute to that risk. ${ }^{6-8}$

Although the impact of treatment for cervical precancer on obstetric sequelae has been extensively described, its effect on the ability to conceive and early pregnancy outcomes has been relatively under-reported. ${ }^{9}{ }^{10}$ Cervical excision removes part of the endocervical canal and as a result the mucus-secreting endocervical glands, which produce secretions facilitating penetration of the sperm and conception. This has been suggested to adversely affect the chances of conception. ${ }^{11}$ The loss of the normal functional cervical structure and the healing process in the regenerated crater after excision may also induce severe stenosis of the cervical os, which may further inhibit sperm penetration and conception. ${ }^{12}$

Two previous small case series ${ }^{1314}$ with limited numbers of patients reported that cervical treatment did not adversely affect the time to conception. A retrospective cohort from Finland of 35000 women with a follow-up of over 250000 women years assessing total pregnancy and live birth rates among treated and untreated women reported no negative effect from treatment. ${ }^{15}$ Treated women were more likely to have more pregnancies and children than the reference population; the pregnancy rates in women with intention to conceive was not reported. ${ }^{15}$ Conversely, the assessment of the actual time to conception in another recent large cohort study from the United States reported that after conisation women took longer to conceive than untreated normal women or women attending colposcopy but not treated (time to conception $>12$ months $16.4 \% v 8.4 \%$, adjusted odds ratio $2.09,95 \%$ confidence interval 1.26 to 3.46$){ }^{16}$

The impact that treatment may have on conception and child bearing causes anxiety to women requiring conisation. Although the impact of treatment on obstetric outcomes has been the subject of previous reports, there is little evidence on the effect that this has on the ability to conceive and early pregnancy outcomes, particularly the rate of miscarriages in the second trimester. The existing published data are limited, often contradictory, and poorly documented. In this systematic review and meta-analysis we assessed the effect of treatment for cervical intraepithelial neoplasia on fertility and early pregnancy outcomes.

\section{Methods}

We included all studies that compared fertility and early pregnancy ( $<24$ weeks' gestation) outcomes in women with or without treatment for cervical intraepithelial neoplasia. We also included all types of treatment, both ablative (laser ablation, cold coagulation, cryotherapy, or radical diathermy) and excisional (cold knife conisation, LLETZ—also known as loop electrosurgical excisional procedure (LEEP), laser conisation, and needle excision of the transformation zone (NETZ) - also known as straight wire excision of the transformation zone (SWETZ)). Studies were included irrespective of the type of untreated reference population - that is, matched or unmatched untreated women, internal self matching with the pregnancies of the same women before treatment, and women attending colposcopy but not receiving treatment. Studies that reported on different treatment methods without specifying the exact type of treatment were also included, even if the outcomes were not reported separately for each treatment modality. We excluded studies that did not include an untreated reference population, compared different treatment techniques without an untreated control, and compared outcomes for treatments performed during pregnancy.

\section{Outcome measures}

We included outcome measures related to fertility and early pregnancy outcomes. The fertility outcomes included total pregnancy rates, pregnancy rates in women wishing to conceive in an unspecified period, and time to conception. The early pregnancy outcomes included rates of miscarriage in the first trimester ( $<12$ weeks' gestation) and second trimester (between 12 and 24 weeks), and overall ( $<24$ weeks); the rate of ectopic pregnancies and hydatiform moles; and the rate for termination of pregnancies.

\section{Retrieval and selection of references}

A search of two electronic databases (Medline and Embase) was conducted targeting reports published between 1960 and March 2014. There was no language restriction. We used keywords such as "cervical intraepithelial neoplasia", "cervical cancer", "fertility", "pregnancy", "miscarriage", "conception", "LLETZ or LEEP”, “conisation", "excision", and "treatment". The full search strategy is included in a supplementary file. In an attempt to identify any articles missed by the initial search or any unpublished data, we hand searched the references of the retrieved articles and meta-analyses and the proceedings of relevant conferences.

Two independent investigators (MK, AM) performed the literature search, the assessment of eligible reports according to the inclusion and exclusion criteria, and the extraction of data. They then compared the results of the search and data extraction; discrepancies were resolved by consensus, with the involvement of a third investigator (MA) if necessary.

The Newcastle-Ottawa score was used to formally assess the quality of the included studies, ${ }^{17}$ according to the MOOSE checklist. ${ }^{18}$

\section{Statistical analysis}

From each study we retrieved the number of events in treated and untreated women for each outcome of interest. We analysed the data separately for each treatment modality-in groups of ablative and excisional techniques and as a whole, irrespective of the method used. We distinguished the different untreated reference populations across studies (matched to factors in the treated group, women with cervical intraepithelial neoplasia but no treatment, self matching or internal controls=before compared with after treatment). A random effects model was used to pool the data, ${ }^{19}$ and Cochrane Revman 5 software to calculate relative risks and 95\% confidence intervals. We used the Cochrane's Q test and $\mathrm{I}^{2}$ statistic to assess heterogeneity among studies for each outcome, corresponding to the percentage of total variance across studies caused by heterogeneity. ${ }^{20}{ }^{21}$ We planned to assess the possible presence of publication bias with funnel plots and formal testing of small study effects for meta-analyses including at least 10 studies. $^{22}$

\section{Results}

We identified 167 potentially eligible studies; 15 fulfilled the inclusion criteria. ${ }^{413-16}$ 23-32 No unpublished studies were identified. All studies were published in English. The details are presented in the PRISMA flowchart ${ }^{33}$ together with the reasons for exclusion (fig $1 \Downarrow$ ).

Table $1 \Downarrow$ shows the characteristics of the included studies and the outcomes examined. We identified 15 studies assessing 
fertility and early pregnancy outcomes in treated and non-treated women. Apart from one prospective study, ${ }^{26}$ the remainder were described as retrospective cohort studies. There were no randomised controlled studies. Three studies examined the impact of cold knife conisation on the studied outcomes, ${ }^{14} 2427$ six on large loop excision of the transformation zone (LLETZ), ${ }^{132325263132}$ one on laser conisation, ${ }^{28}$ and the remaining five on multiple treatment techniques. ${ }^{415162930}$ Some studies adjusted the untreated population for known risk factors for adverse reproductive outcomes, ${ }^{13} 14232531$ some included women with cervical intraepithelial neoplasia who received no treatment, ${ }^{32}$ some did not match for any confounders, ${ }^{26}$ others used internal controls (outcomes in the same women before and after treatment), ${ }^{24} 27{ }^{30}$ whereas some performed a logistic regression to control for known confounders. ${ }^{415} 1629$ Two of the studies using internal controls also matched for known confounders such as age and parity. ${ }^{27}{ }^{30}$ The data were retrieved from hospital records, questionnaires, and national registries. The number of participants in the treated and untreated groups ranged from 21 to 15108 and from 20 to 2164006 , respectively (table 1).

Table 1 shows the Newcastle-Ottawa scores for quality assessment of the observational studies. All the studies scored at least 7. A more detailed assessment is included in the supplementary file.

Table $2 \Downarrow$ show the fertility and early pregnancy outcomes assessed in each of the included studies. Tables $3 \Downarrow$ and $4 \Downarrow$ show the pooled results.

\section{Fertility outcomes}

The meta-analysis did not provide any evidence to suggest that treatment for cervical intraepithelial neoplasia adversely affects the chances of conception (table 3 and fig $2 \Downarrow$ ).

The results of the individual studies on the overall pregnancy rate varied. Two studies did not report any significant differences, ${ }^{13} 32$ whereas the remaining two described significantly higher overall pregnancy rates for the treated population. ${ }^{13}{ }^{30}$ Specifically, one study ${ }^{30}$ reported that women treated with laser conisation or ablation had high pregnancy rates $(277 / 433 ; 64 \%)$ compared with untreated women (177/433; $41 \%$ ) (relative risk $1.56,95 \%$ confidence interval 1.37 to 1.79 ). Similarly, another study ${ }^{15}$ reported higher pregnancy rates for treated women (multiple methods: cold knife conisation,

LLETZ, laser conisation, laser ablation, cryotherapy) compared with untreated women $(2578 / 6179 ; 41.7 \%$ v 11642/30463; $38.2 \%$, respectively) $(1.09,1.06$ to 1.13$)$. The pooled analysis for the overall pregnancy rate assessed in four studies was higher for treated women than for untreated women (43\% and 38\%) $(1.29,1.02$ to 1.64$)$, although heterogeneity in the studies was high $(\mathrm{P}<0.0001$, fig 2$)$.

Two small studies assessed the pregnancy rate in women with an intention to conceive, ${ }^{14} 32$ and in both the result was no different between treated and untreated women. The pooled meta-analysis also confirmed that treated and untreated women did not differ significantly (two studies; relative risk $0.93,95 \%$ confidence interval 0.80 to 1.08 , fig $3 \Downarrow$ ).

Three small studies described the time needed to conceive. ${ }^{131416}$ Two of them ${ }^{13}{ }^{14}$ reported non-significant differences, although one ${ }^{16}$ suggested that the proportion of women who required more than 12 months to conceive was significantly higher for treated women (all methods, not specified) $(25 / 152 ; 16 \%)$ than for all untreated women $(86 / 1021 ; 8.4 \%)$ (relative risk 1.95 , $95 \%$ confidence interval 1.29 to 2.95 ) or compared with non-treated women attending for colposcopy $(13 / 151 ; 9 \%)(1.91$,
1.02 to 3.59$)$. The pooled meta-analysis suggested that treatment did not adversely affect the proportion of women who required more than 12 months to conceive (three studies; $14.7 \%$ v $9.2 \%$, $1.45,0.89$ to $2.37, \mathrm{P}=0.14$, fig 3 ). The remaining intervals to conception that were assessed were also not significantly affected $(\mathrm{P}>0.05)$.

\section{Early pregnancy outcomes}

Early pregnancy outcomes were assessed in 14 studies. Table 4 and figures $4 \Downarrow$ and $5 \Downarrow$ present the results of the meta-analysis on the early pregnancy outcomes.

All studies reporting on the overall rate for miscarriage,,$^{13-15} 2426-283132$ apart from one, ${ }^{30}$ reported no significant differences between treated and untreated populations. One study ${ }^{30}$ reported a protective effect for treated women compared with untreated controls (11.4\% and 18.6\%) (relative risk $0.60,95 \%$ confidence interval 0.38 to 0.94 , $\mathrm{P}=0.03$ ). The pooled analysis for the total rate for miscarriage between treated and untreated women was not significantly different (10 studies; $4.6 \% v 2.8 \%, 1.04,0.90$ to 1.21) for any of the methods assessed (fig 4).

Four studies reported on miscarriage rates in the first trimester, separately ${ }^{14} 2728$; the included studies did not differ significantly. The pooled meta-analysis for miscarriage rates in the first trimester showed no significant differences $(9.8 \%$ $v 8.4 \% ; 1.16,0.80$ to 1.69 ) (fig 5).

Eight studies reported on miscarriage rates in the second trimester. ${ }^{4}{ }^{14} 23-25{ }^{27-29}$ Seven did not report significant differences, whereas one with a large sample size ${ }^{4}$ showed that treated women had a significantly higher rate of miscarriage in the second trimester $(226 / 15108 ; 1.5 \%)$ when compared with untreated $(8501 / 2164006 ; 0.4 \%, 3.81,3.34$ to 4.34$)$ or internal controls $(209 / 57136 ; 0.4 \%, 4.09,3.39$ to 4.93$)$. In the pooled meta-analysis, we found that cervical treatment significantly increased the risk of miscarriage in the second trimester. This outcome was assessed in eight studies and 16558 treated women. The rate was higher for treated than for untreated women $(1.6 \%$ and $0.4 \%, 2.60,1.45$ to 4.67 , fig 5$)$. There was no significant interstudy heterogeneity.

The rate of ectopic pregnancy was also higher for treated than for untreated women $(1.6 \%$ and $0.8 \%$ ) (six studies, 1.89, 1.50 to 2.39 ), whereas the rate for molar pregnancy did not differ $(\mathrm{P}>0.05)$. The termination of pregnancy rate was higher in women with a history of treatment than in untreated controls (12.2\% and $7.4 \%$ ) (seven studies, $1.71,1.31$ to 2.22 ).

Given the low number of studies included in each of the meta-analyses, the risk of publication bias and the potential sources of heterogeneity could not be assessed formally.

\section{Discussion}

Cervical treatment has been associated with an increased risk of adverse obstetric sequelae and preterm birth in subsequent pregnancies. ${ }^{2} 3734$ More recent data suggest that cervical intraepithelial neoplasia itself may partly contribute to that risk, ${ }^{6}$ while there seems to be a "dose-response" effect documented for treatment; the larger the excision or proportion of cervix removed, the larger and more serious the effect may be from treatment. $^{5}{ }^{735-38}$

It has been suggested that cervical treatment may impair future fertility for women as a result of cervical stenosis and the reduction of cervical glands and mucus. ${ }^{10}{ }^{11}$ Similarly, concerns have been raised that the rate of miscarriages in the second trimester is also increased in treated populations. To date, the 
impact on fertility and early pregnancy outcomes has not been systematically assessed in the published literature.

This systematic review and meta-analysis demonstrates that there is no evidence to support that treatment for cervical precancer adversely affects fertility outcomes and the chances to conceive. Although the pregnancy rate in women with an intention to conceive was no different, the overall pregnancy rate was higher for women who received treatment than for untreated controls; the heterogeneity across studies was significant. The higher pregnancy rate in the treated population may be explained by sexual and behavioural characteristics in women with cervical precancer or their increased anxiety for their future fertility after treatment. The time required to conceive was overall similar among the compared populations. There was a trend towards longer conception time for treated women, but the differences were not significant. Although this may hint at an impact of treatment on fertility, it may also be explained by clinicians' recommendation to avoid conception during the early postoperative period and until the first follow-up assessment confirms the absence of residual disease.

Although the rates for miscarriage overall and in the first trimester did not differ, this meta-analysis suggests that treatment for cervical intraepithelial neoplasia increases the risk of miscarriage in the second trimester, possibly as a result of cervical incompetence after proportionally large excisions. The incidence of miscarriages in the second trimester is low and therefore individual small cohorts often failed to reach significant results previously. This is the first meta-analysis combining multiple studies to show statistically significant differences. Although the results of the analysis are dominated by one large study, ${ }^{4}$ this is not an outlier, and exclusion of this study from the analysis yielded similar results. This study included various treatment modalities (knife, laser, and LLETZ) and the outcomes for each individual technique were not available from the registry linkage. Most deliveries (87\%) were after the 1990s and the introduction of LLETZ, although the timing of treatment was unclear. The higher number of ectopic pregnancies and terminations in the treated population possibly reflects the characteristics of women with cervical precancer, who are known to be at a higher risk of sexually transmitted disease and unplanned pregnancies and not related to cervical intraepithelial neoplasia treatment. It may also be that a dysfunction in the immune defences and the protective mechanisms makes some women more prone to ascending infections and also persistence of human papillomavirus and cervical precancer. Conversely, human papillomavirus infection itself may have an effect on antimicrobials in the cervical mucus.

\section{Strengths and limitations of this review}

This is the first systematic review to show that fertility is probably not impaired after treatment. The results, however, should be interpreted with caution. The included studies were heterogeneous for study design, included populations, matching for confounders, length of follow-up, and outcome verification. The number of studies and the study size were often small for many of the reported outcomes and the outcomes of interest were difficult to objectively measure. Although the interstudy heterogeneity was not significant for all outcomes apart from one, the number of studies was small and the analysis could be affected by the addition of further studies. The effect was not significantly changed by sensitivity analysis excluding some of the largest studies. All studies apart from one ${ }^{26}$ described retrospective cohorts and are prone to possible bias. The data were derived from self reporting, clinic datasets, telephone contacts, and postal questionnaires or national registries and may represent incomplete and selected data. Early pregnancy outcomes are often less well reported than outcomes in the third trimester. The level of over-reporting or under-reporting may be different for treated and untreated women and the impact of this is difficult to assess. Reporting may be better in the treated group owing to easier access to gynaecological services or, conversely, may be lower in women with cervical intraepithelial neoplasia, who often belong to lower socioeconomic classes that are likely to be less compliant with recommended medical care. Studies that assess fertility outcomes post-treatment are difficult owing to the multifactorial nature of the condition (for example, male, lifestyle). It is often difficult to design such a study and yet eliminate all of the confounding variables.

The analysis included studies with different designs, using comparisons between and among women and mixed matching. It was not possible to carry out subgroup analyses for the different comparison groups because of the limited number of studies in each group. It is unlikely that the use of different comparison groups generated bias because the studies using different comparators showed similar direction and magnitude of effect. Four studies used comparisons of the same women before and after treatment; two of these also matched for known confounders. A sensitivity analysis that excluded the four studies using internal comparators and a sensitivity analysis that excluded old or poor quality studies did not significantly change the direction or the magnitude of the effect of the meta-analysis. A separate analysis for different treatment modalities was done, but the power to identify significant findings was limited owing to the lack of large studies. An analysis that would stratify according to the depth of the cone or parity was also not feasible, as these data were not reported by the individual studies. It is likely that the risk increases with greater proportions of the cervix removed. Future studies should try to stratify the risk of miscarriages in the second trimester and the chances of conception according to the depth and proportion of cervix excised. Inability to adjust for size of excision and treatment technique may mask the true effect that deep conisations could have on fertility and, conversely, the lack of effect that small excisions $(<10 \mathrm{~mm})$ may have on the risk of miscarriages in the second trimester.

\section{Possible mechanisms}

The exact mechanism that explains the increased risk of miscarriages in the second trimester and preterm birth associated with cervical intraepithelial neoplasia and its treatment is unclear. Although most obstetricians would think that this increase in risk is due to a simple lack of mechanical support, histological changes in the healed cervix affecting the tensile strength $^{39}$ or changes in the innate immune system and the vaginal microenvironment probably also make an important contribution. The uterus in pregnancy is protected from ascending infection by the cervix, its mucous plug, and its synthesis of antibacterial compounds, and by a "benign" lactobacillus dominated vaginal microflora ${ }^{40}$ There is a clear link between infection or inflammation and preterm birth. Removing part of the cervix or simply being infected with human papillomavirus may impair the host's defense mechanisms and change the chemical microenvironment and as a result affect the vaginal microbiome or the production of natural antimicrobials by the cervix. ${ }^{41}$ It may also be that some women share immunological variations and other factors that co-associate with both cervical intraepithelial neoplasia and preterm birth and that make them susceptible to not only persistent infections with human papillomavirus but also ascending infections and preterm birth when pregnant. A better 
understanding of these factors may enable selection of women at risk and prevention with cause directed strategies. ${ }^{42-46}$ It may be possible to manipulate the vaginal microbiota through microbiome gene regulations and probiotic and prebiotic treatments to establish a healthy environment, combat disease, and improve health. ${ }^{42} 43$

\section{Conclusion and policy implications}

Despite the limitations of this meta-analysis, we found no evidence to suggest that fertility is affected by treatment for cervical intraepithelial neoplasia, although the risk of miscarriages in the second trimester was significantly increased. The risk of second trimester miscarriages with less aggressive treatment, such as LLETZ, particularly for small excisions, or the risk for reduced fertility in proportionally large conisations, remains unclear. Future large, well designed studies are required to carefully explore possible associations between treatment for cervical intraepithelial neoplasia and subsequent fertility and early and late pregnancy outcomes, stratifying by the size of excision and treatment technique. The exact mechanism and the extent of excision that increase the risk remain unknown. Caution should prevail when considering treatment in young women who may want future pregnancies. Until more evidence becomes available, it is important to remove as little tissue as possible, especially in nulliparous women with a small cervix, without compromising the eradication of the disease. More sensitive tests such as those for human papillomavirus DNA should be used to improve the detection of residual or recurrent lesions after treatment and to minimise the risk of future cancer in young women. ${ }^{47}$ Every effort should be made to optimise both reproductive and oncological outcomes for women requiring treatment. ${ }^{37} 48$

Contributors: MK, PB, and EP conceived and designed the study. MK, $\mathrm{AM}$, and SMS acquired and collated the data. MK, AM, and MA analysed the data. All authors drafted and revised the manuscript critically for important intellectual content, gave final approval of the version to be published, and contributed to the manuscript. MK had full access to all the data in the study and the final responsibility for the decision to submit for publication and is the guarantor. PB and EP are joint last authors.

Funding: The study was supported by the Imperial Healthcare NHS Trust Biomedical Research Centre grant P45272. MK received support and a research award from the British Society of Colposcopy and Cervical Pathology. AM and MK were supported by the Imperial College Healthcare Charity Fellowship. MA was supported by seventh framework programme of DG research of the European Commission, through the COHEAHR Network (grant No 603019); the Institut national du Cancer (Paris, France) through the COSPCC study (Conséquences obstétricales du (sur)traitement des précurseurs du cancer du col utérin) and by European Federation of Colposcopy.

Competing interests: All authors have completed the ICMJE uniform disclosure form at www.icmje.org/coi_disclosure.pdf and declare: no support from any organisation for the submitted work; no financial relationships with any organisations that might have an interest in the submitted work in the previous three years; no other relationships or activities that could appear to have influenced the submitted work.

Ethical approval: Not required.

Data sharing: No additional data available.

Transparency: The lead author MK (the manuscript's guarantor) affirms that the manuscript is an honest, accurate, and transparent account of the study being reported; that no important aspects of the study have been omitted; and that any discrepancies from the study as planned have been explained.
1 Quinn $\mathrm{M}, \mathrm{Babb} \mathrm{P}$, Jones J, Allen E. Effect of screening on incidence of and mortality from cancer of cervix in England: evaluation based on routinely collected statistics. BMJ 1999;318:904-8.

2 Kyrgiou M, Koliopoulos G, Martin-Hirsch P, Arbyn M, Prendiville W, Paraskevaidis E. Obstetric outcomes after conservative treatment for intraepithelial or early invasive cervical lesions: systematic review and meta-analysis. Lancet 2006;367:489-98.

3 Arbyn M, Kyrgiou M, Simoens C, Raifu AO, Koliopoulos G, Martin-Hirsch P, et al. Perinatal mortality and other severe adverse pregnancy outcomes associated with treatment of cervical intraepithelial neoplasia: meta-analysis. BMJ 2008;337:a1284.

4 Albrechtsen S, Rasmussen S, Thoresen S, Irgens LM, Iversen OE. Pregnancy outcome in women before and after cervical conisation: population based cohort study. BMJ 2008;337:a1343

5 Noehr B, Jensen A, Frederiksen K, Tabor A, Kjaer SK. Depth of cervical cone removed by loop electrosurgical excision procedure and subsequent risk of spontaneous preterm delivery. Obstetr Gynecol 2009;114:1232-8.

6 Castanon A, Brocklehurst P, Evans H, Peebles D, Singh N, Walker P, et al. Risk of preterm birth after treatment for cervical intraepithelial neoplasia among women attending colposcopy in England: retrospective-prospective cohort study. BMJ 2012;345:e5174.

7 Kyrgiou M, Arbyn M, Martin-Hirsch P, Paraskevaidis E. Increased risk of preterm birth after treatment for CIN. BMJ 2012;345:e5847.

8 Bruinsma F, Lumley J, Tan J, Quinn M. Precancerous changes in the cervix and risk of subsequent preterm birth. Br J Obstetr Gynaecol 2007;114:70-80.

9 Paraskevaidis E, Kyrgiou M, Martin-Hirsch P. Have we dismissed ablative treatment too soon in colposcopy practice? Br J Obstetr Gynaecol 2007;114:3-4

10 Hammond RH, Edmonds DK. Does treatment for cervical intraepithelial neoplasia affect fertility and pregnancy? BMJ 1990;301:1344-5.

11 Kennedy S, Robinson J, Hallam N. LLETZ and infertility. Br J Obstetr Gynaecol 1993;100:965

12 Luesley DM, McCrum A, Terry PB, Wade-Evans T, Nicholson HO, Mylotte MJ, et al. Complications of cone biopsy related to the dimensions of the cone and the influence of prior colposcopic assessment. Br J Obstetr Gynaecol 1985;92:158-64.

13 Bigrigg A, Haffenden DK, Sheehan AL, Codling BW, Read MD. Efficacy and safety of large-loop excision of the transformation zone. Lancet 1994;343:32-4.

14 Weber T, Obel E. Pregnancy complications following conization of the uterine cervix (I). Acta Obstetr Gynecol Scand 1979;58:259-63

15 Kalliala I, Anttila A, Dyba T, Hakulinen T, Halttunen M, Nieminen P. Pregnancy incidence and outcome among patients with cervical intraepithelial neoplasia: a retrospective cohort study. Br J Obstetr Gynaecol 2012;119:227-35.

16 Spracklen CN, Harland KK, Stegmann BJ, Saftlas AF. Cervical surgery for cervical intraepithelial neoplasia and prolonged time to conception of a live birth: a case-control study. Br J Obstetr Gynaecol 2013;120:960-5.

17 Wells GA, Shea B, O'Connell D, Peterson J, Welch V, Losos M, et al. The Newcastle-Ottawa Scale (NOS) for assessing the quality of nonrandomised studies in meta-analyses. 2010. www.ohri.ca/programs/clinical_epidemiology/nos_manual.pdt.

18 Stroup DF, Berlin JA, Morton SC, Olkin I, Williamson GD, Rennie D, et al. Meta-analysis of observational studies in epidemiology: a proposal for reporting. Meta-analysis Of Observational Studies in Epidemiology (MOOSE) group. JAMA 2000;283:2008-12.

19 DerSimonian R, Laird N. Meta-analysis in clinical trials. Control Clin Trials 1986;7:177-88.

20 Cochran WG. The combination of estimates from different experiments. Biometrics 1954;10:101-29.

21 Higgins JP, Thompson SG, Deeks JJ, Altman DG. Measuring inconsistency in meta-analyses. BMJ 2003;327:557-60.

22 Harbord RM, Harris RJ, Sterne JAC. Updated tests for small-study effects in meta-analyses. Stata J 2009;9:197-210.

23 Blomfield PI, Buxton J, Dunn J, Luesley DM. Pregnancy outcome after large loop excision of the cervical transformation zone. Am J Obstetr Gynecol 1993;169:620-5.

24 Buller RE, Jones HW, 3rd. Pregnancy following cervical conization. Am J Obstetr Gynecol 1982;142:506-12

25 Cruickshank ME, Flannelly G, Campbell DM, Kitchener HC. Fertility and pregnancy outcome following large loop excision of the cervical transformation zone. Br J Obstetr Gynaecol 1995;102:467-70

26 Frega A, Sesti F, De Sanctis L, Pacchiarotti A, Votano S, Biamonti A, et al. Pregnancy outcome after loop electrosurgical excision procedure for cervical intraepithelial neoplasia. Int J Gynaecol Obstetr 2013;122:145-9.

27 Larsson G, Grundsell H, Gullberg B, Svennerud S. Outcome of pregnancy after conization. Acta Obstetr Gynecol Scand 1982;61:461-6.

28 Sagot $\mathrm{P}$, Caroit $\mathrm{Y}$, Winer N, Lopes $\mathrm{P}$, Boog G. Obstetrical prognosis for carbon dioxide laser conisation of the uterine cervix. Eur J Obstetr Gynecol Reprod Biol 1995;58:53-8.

29 Sjoborg KD, Vistad I, Myhr SS, Svenningsen R, Herzog C, Kloster-Jensen A, et al. Pregnancy outcome after cervical cone excision: a case-control study. Acta Obstet Gynecol Scand 2007;86:423-8.

30 Spitzer M, Herman J, Krumholz BA, Lesser M. The fertility of women after cervical laser surgery. Obstetr Gynecol 1995;86(4 Pt 1):504-8.

31 Tan L, Pepra E, Haloob RK. The outcome of pregnancy after large loop excision of the transformation zone of the cervix. J Obstetr Gynaecol 2004:24:25-7.

32 Turlington WT, Wright BD, Powell JL. Impact of the loop electrosurgical excision procedure on future fertility. J Reprod Med 1996;41:815-8.

33 Moher D, Liberati A, Tetzlaff J, Altman DG, Group P. Preferred reporting items for systematic reviews and meta-analyses: the PRISMA Statement. Open Med 2009;3:e123-30.

34 Jakobsson M, Gissler M, Sainio S, Paavonen J, Tapper AM. Preterm delivery after surgical treatment for cervical intraepithelial neoplasia. Obstetr Gynecol 2007:109(2 Pt 1):309-13.

35 Founta C, Arbyn M, Valasoulis G, Kyrgiou M, Tsili A, Martin-Hirsch P, et al. Proportion of excision and cervical healing after large loop excision of the transformation zone for cervical intraepithelial neoplasia. Br J Obstetr Gynaecol 2010;117:1468-74.

36 Khalid S, Dimitriou E, Conroy R, Paraskevaidis E, Kyrgiou M, Harrity C, et al. The thickness and volume of LLETZ specimens can predict the relative risk of pregnancy-related morbidity. Br J Obstetr Gynaecol 2012;119:685-91.

37 Arbyn M, Kyrgiou M, Gondry J, Petry KU, Paraskevaidis E. Long term outcomes for women treated for cervical precancer. BMJ 2014;348:f7700.

38 Kyrgiou M, Valasoulis G, Stasinou SM, Founta C, Athanasiou A, Bennett P, et al. Proportion of cervical excision for $\mathrm{CIN}$ as a predictor of pregnancy outcomes. Int J Gynaecol Obstetr 2014; (in press). 


\section{What is already known on this topic}

Treatment for cervical intraepithelial neoplasia increases the risk of preterm birth and this risk increases with increasing depth of excision A large retrospective cohort reported that treated women had higher pregnancy rates than the untreated population ${ }^{15}$

However, another recent large series reported that women after conisation take longer to conceive than untreated normal women or women attending colposcopy but not treated ${ }^{16}$

\section{What this study adds}

There is no evidence to support that fertility is affected after treatment for cervical precancer, although the rate of miscarriages in the second trimester was increased

Future studies should carefully explore associations between treatment and subsequent reproductive outcomes stratifying by the size of excision and treatment technique

39 Phadnis SV, Atilade A, Bowring J, Kyrgiou M, Young MP, Evans H, et al. Regeneration of cervix after excisional treatment for cervical intraepithelial neoplasia: a study of collagen distribution. Br J Obstetr Gynaecol 2011;118:1585-91.

40 Ravel J, Gajer P, Abdo Z, Schneider GM, Koenig SS, McCulle SL, et al. Vaginal microbiome of reproductive-age women. Proc Natl Acad Sci U S A 2011;108(Supp 1):4680-7.

41 Human Microbiome Project Consortium. Structure, function and diversity of the healthy human microbiome. Nature 2012;486:207-14.

42 Holmes E, Kinross J, Gibson GR, Burcelin R, Jia W, Pettersson S, et al. Therapeutic modulation of microbiota-host metabolic interactions. Sci Trans/ Med 2012;4:137rv6.

43 Holmes E, Li JV, Marchesi JR, Nicholson JK. Gut microbiota composition and activity in relation to host metabolic phenotype and disease risk. Cell Metab 2012;16:559-64.

44 Nicholson JK, Holmes E, Kinross J, Burcelin R, Gibson G, Jia W, et al. Host-gut microbiota metabolic interactions. Science 2012;336:1262-7.

45 Li JV, Ashrafian H, Bueter M, Kinross J, Sands C, le Roux CW, et al. Metabolic surgery profoundly influences gut microbial-host metabolic cross-talk. Gut 2011;60:1214-23.

46 Jimenez B, Mirnezami R, Kinross J, Cloarec O, Keun HC, Holmes E, et al. 1H HR-MAS NMR spectroscopy of tumor-induced local metabolic "field-effects" enables colorectal cancer staging and prognostication. J Proteome Res 2013:12:959-68.
47 Arbyn M, Ronco G, Anttila A, Meijer CJ, Poljak M, Ogilvie G, et al. Evidence regarding human papillomavirus testing in secondary prevention of cervical cancer. Vaccine 2012;30(Suppl 5):F88-99.

48 Strander B, Hallgren J, Sparen P. Effect of ageing on cervical or vaginal cancer in Swedish women previously treated for cervical intraepithelial neoplasia grade 3: population based cohort study of long term incidence and mortality. BMJ 2014;348:77361.

\section{Accepted: 3 October 2014}

\section{Cite this as: BMJ 2014;349:g6192}

This is an Open Access article distributed in accordance with the Creative Commons Attribution Non Commercial (CC BY-NC 4.0) license, which permits others to distribute, remix, adapt, build upon this work non-commercially, and license their derivative works on different terms, provided the original work is properly cited and the use is non-commercial. See: http://creativecommons.org/licenses/by-nc/4.0/. 


\section{Tables}

\section{Table 1/ Characteristics of included studies comparing fertility and early pregnancy outcomes with untreated women}

\begin{tabular}{llccccc} 
Study & \multicolumn{1}{c}{ Matching factors } & Procedure & Treated & Untreated & Source of data \\
$\begin{array}{l}\text { Weber et al } \\
1979^{14}\end{array}$ & $\begin{array}{l}\text { Partly age and partly internal } \\
\text { matching }\end{array}$ & $\begin{array}{l}\text { Cold knife } \\
\text { conisation }\end{array}$ & 21 & 20 & $\begin{array}{l}\text { Interview, postal } \\
\text { questionnaire }\end{array}$
\end{tabular}

Outcomes

Newcastle-Ottawa

Pregnancy rates in women score $^{\star}$

$1979^{14}$ matching $\quad$ conisation wishing to conceive conceptions within given time; miscarriages (total, first and second trimester); terminations

\begin{tabular}{|c|c|c|c|c|c|c|c|}
\hline & & & & & & & \\
\hline $\begin{array}{l}\text { Larsson et al } \\
1982^{27}\end{array}$ & $\begin{array}{l}\text { Internal }{ }^{*} \text {; comparable for age, } \\
\text { parity, socioeconomic status, } \\
\text { smoking, surgical } \\
\text { interventions, various } \\
\text { diseases }\end{array}$ & $\begin{array}{l}\text { Cold knife } \\
\text { conisation }\end{array}$ & 294 & 341 & Hospital records & $\begin{array}{l}\text { Miscarriages (total, first and } \\
\text { second trimester); ectopic } \\
\text { pregnancies; terminations }\end{array}$ & 9 \\
\hline $\begin{array}{l}\text { Buller et al } \\
1982^{24}\end{array}$ & Internal† & $\begin{array}{l}\text { Cold knife } \\
\text { conisation }\end{array}$ & 88 & 106 & Hospital records & $\begin{array}{l}\text { Miscarriages (total, first and } \\
\text { second trimester); ectopic } \\
\text { pregnancies; molar } \\
\text { pregnancies; terminations }\end{array}$ & 8 \\
\hline $\begin{array}{l}\text { Blomfield et al } \\
1993^{23}\end{array}$ & Age, parity, ethnicity & LLETZ & 40 & 80 & Hospital records & $\begin{array}{l}\text { Miscarriages (second } \\
\text { trimester) }\end{array}$ & 9 \\
\hline $\begin{array}{l}\text { Bigrigg et al } \\
1994^{13}\end{array}$ & $\begin{array}{l}\text { Age, geographical area; all } \\
\text { controls had negative smear } \\
\text { test results }\end{array}$ & LLETZ & 76 to 229 & 66 to $299 \ddagger$ & $\begin{array}{l}\text { Telephone } \\
\text { interview, postal } \\
\text { questionnaire }\end{array}$ & $\begin{array}{l}\text { Total pregnancy rates; } \\
\text { conceptions within given } \\
\text { time; miscarriages (total); } \\
\text { ectopic pregnancies }\end{array}$ & 7 \\
\hline $\begin{array}{l}\text { Cruickshank et } \\
\text { al } 1995^{25}\end{array}$ & $\begin{array}{l}\text { Age, parity, height, smoking } \\
\text { status, and partner's social } \\
\text { class }\end{array}$ & LLETZ & 149 & 298 & $\begin{array}{l}\text { Postal } \\
\text { questionnaire } \\
\text { (treated); maternity } \\
\text { databank } \\
\text { (untreated) }\end{array}$ & $\begin{array}{l}\text { Miscarriages (second } \\
\text { trimester) }\end{array}$ & 8 \\
\hline $\begin{array}{l}\text { Sagot et al } \\
1995^{28}\end{array}$ & Internal† & Laser conisation & 71 & 82 & Hospital records & $\begin{array}{l}\text { Miscarriages (total, first and } \\
\text { second trimester); ectopic } \\
\text { pregnancies; molar } \\
\text { pregnancies; terminations }\end{array}$ & 8 \\
\hline $\begin{array}{l}\text { Spitzer et al } \\
1995^{30}\end{array}$ & $\begin{array}{l}\text { Internalf; matched for age } \\
\text { and parity with population } \\
\text { from pretreatment interval of } \\
\text { same patients }\end{array}$ & $\begin{array}{l}\text { Laser conisation; } \\
\text { laser ablation }\end{array}$ & 433 & 433 & $\begin{array}{l}\text { Telephone } \\
\text { interview, } \\
\text { questionnaire }\end{array}$ & $\begin{array}{l}\text { Total pregnancy rates; } \\
\text { miscarriages (total); ectopic } \\
\text { pregnancies; terminations }\end{array}$ & 8 \\
\hline $\begin{array}{l}\text { Turlington et al } \\
1996^{32}\end{array}$ & $\begin{array}{l}\text { Untreated women had } \\
\text { colposcopy and biopsy but no } \\
\text { treatment }\end{array}$ & LLETZ & 54 & 57 & $\begin{array}{l}\text { Telephone } \\
\text { interview, mail } \\
\text { questionnaire }\end{array}$ & $\begin{array}{l}\text { Total pregnancy rates; } \\
\text { pregnancy rates in women } \\
\text { wishing to conceive; } \\
\text { miscarriages (total); } \\
\text { terminations }\end{array}$ & 7 \\
\hline Tan et al $2004^{31}$ & Age, parity, period of delivery & LLETZ & 119 & 119 & Hospital records & Miscarriages (total) & 9 \\
\hline $\begin{array}{l}\text { Sjoberg et al } \\
2007^{29}\end{array}$ & $\begin{array}{l}\text { Age, parity, plurality, and } \\
\text { regression analysis for } \\
\text { smoking status, marital } \\
\text { status, and education }\end{array}$ & $\begin{array}{l}\text { Laser conisation; } \\
\text { LLETZ }\end{array}$ & 742 & 742 & National registry & $\begin{array}{l}\text { Miscarriages (second } \\
\text { trimester) }\end{array}$ & 8 \\
\hline $\begin{array}{l}\text { Albrechtesen et } \\
\text { al } 2008^{4}\end{array}$ & $\begin{array}{l}\text { Unmatched-regression } \\
\text { analysis for age and birth } \\
\text { order }\end{array}$ & $\begin{array}{l}\text { Cold knife } \\
\text { conisation; laser } \\
\text { conisation; LLETZ }\end{array}$ & 15108 & 2164006 & National registry & $\begin{array}{l}\text { Miscarriages (second } \\
\text { trimester) }\end{array}$ & 9 \\
\hline $\begin{array}{l}\text { Kalliala et al } \\
2012^{15}\end{array}$ & $\begin{array}{l}\text { Unmatched-regression } \\
\text { analysis for number of } \\
\text { pregnancies and children, } \\
\text { age, municipality }\end{array}$ & $\begin{array}{l}\text { LLETZ; cold knife } \\
\text { conisation; } \\
\text { cryotherapy; laser } \\
\text { conisation; laser } \\
\text { ablation }\end{array}$ & 6179 & 30436 & $\begin{array}{l}\text { Hospital records, } \\
\text { national registries }\end{array}$ & Total pregnancy rates & 9 \\
\hline $\begin{array}{l}\text { Frega et al } \\
2013^{26}\end{array}$ & $\begin{array}{l}\text { Unmatched but only } \\
\text { nulliparous, white ethnic } \\
\text { group included }\end{array}$ & LLETZ & 1329 & 462 & Prospective records & $\begin{array}{l}\text { Miscarriages (gestation not } \\
\text { specified) }\end{array}$ & 8 \\
\hline
\end{tabular}


Table 1 (continued)

\begin{tabular}{|c|c|c|c|c|c|c|c|}
\hline Study & Matching factors & Procedure & Treated & Untreated & Source of data & Outcomes & $\begin{array}{c}\text { Newcastle-Ottawa } \\
\text { score }^{\star}\end{array}$ \\
\hline $\begin{array}{l}\text { Spracklen et al } \\
2013^{16}\end{array}$ & $\begin{array}{l}\text { Unmatched-regression } \\
\text { analysis for age, education, } \\
\text { income, race, parity, body } \\
\text { mass index, smoking status, } \\
\text { cervical surgery, case status }\end{array}$ & $\begin{array}{l}\text { Cold knife } \\
\text { conisation; LLETZ; } \\
\text { cryotherapy; laser } \\
\text { ablation }\end{array}$ & 152 & $\begin{array}{c}151 \\
\text { colposcopy } \\
\text { only; } 1021 \\
\text { untreated }\end{array}$ & $\begin{array}{l}\text { Birth registries, } \\
\text { telephone interview }\end{array}$ & $\begin{array}{l}\text { Conceptions within given } \\
\text { time }\end{array}$ & 8 \\
\hline
\end{tabular}

LLETZ=large loop excision of the transformation zone.

All study designs were retrospective cohort, except for Frega et al, ${ }^{26}$ which was a prospective cohort design.

${ }^{*}$ Score for quality assessment in observational studies: maximum 9, minimum 0 (see supplementary appendix 2).

†Self matching is comparison of pregnancies in same woman before and after treatment.

‡Different number of cases and controls for every outcome in same study. 


\begin{tabular}{|c|c|c|c|}
\hline \multirow[b]{2}{*}{ Treatment and fertility outcomes } & \multicolumn{2}{|c|}{ No with outcome/No in group (\%) } & \multirow[b]{2}{*}{ Relative risk (95\% Cl) } \\
\hline & Treated group & Untreated group & \\
\hline \multicolumn{4}{|l|}{ Weber et al $1979^{14}$} \\
\hline Cold knife conisation: & $\mathrm{n}=21$ & $\mathrm{n}=20$ & \\
\hline PRIC & $18(86)$ & $18(90)$ & $0.95(0.76$ to 1.20$)$ \\
\hline \multicolumn{4}{|l|}{ Time to conception (months): } \\
\hline $0-3$ & $10(48)$ & $9(45)$ & $1.06(0.55$ to 2.05$)$ \\
\hline $0-6$ & $12(57)$ & $11(55)$ & $1.04(0.60$ to 1.79$)$ \\
\hline $0-9$ & $14(67)$ & $13(65)$ & $1.03(0.66$ to 1.59$)$ \\
\hline $0-12$ & $14(67)$ & $14(70)$ & 0.95 (0.63 to 1.44$)$ \\
\hline $0-24$ & $18(86)$ & $18(90)$ & $0.95(0.76$ to 1.20$)$ \\
\hline Miscarriages: & $\mathrm{n}=66$ & $\mathrm{n}=55$ & \\
\hline Total & $12(18)$ & $6(11)$ & $1.67(0.67$ to 4.15$)$ \\
\hline First trimester & $8(12)$ & $5(9)$ & $1.33(0.46$ to 3.84$)$ \\
\hline Second trimester & $4(6)$ & $1(2)$ & 3.33 (0.38 to 28.96$)$ \\
\hline Termination of pregnancy & $5(8)$ & $1(2)$ & 4.17 (0.50 to 34.61$)$ \\
\hline \multicolumn{4}{|l|}{ Buller et al $1982^{24}$} \\
\hline Cold knife conisation: & $n=88$ & $\mathrm{n}=106$ & \\
\hline \multicolumn{4}{|l|}{ Miscarriages: } \\
\hline Total & $11(12.5)$ & $10(9)$ & $1.20(0.53$ to 2.76$)$ \\
\hline First trimester & $9(10)$ & $8(7.5)$ & 1.36 (0.55 to 3.36$)$ \\
\hline Second trimester & $1(1)$ & $2(2)$ & 0.60 (0.06 to 6.53$)$ \\
\hline Ectopic pregnancy & $3(3)$ & $1(1)$ & 3.61 (0.38 to 34.13$)$ \\
\hline Molar pregnancy & $0(0)$ & $1(1)$ & $0.4(0.02$ to 9.88$)$ \\
\hline Termination of pregnancy & $24(27)$ & $15(14)$ & 1.93 (1.08 to 3.44$)$ \\
\hline \multicolumn{4}{|l|}{ Larsson et al $1982^{27}$} \\
\hline Cold knife conisation: & $\mathrm{n}=294$ & $\mathrm{n}=341$ & \\
\hline \multicolumn{4}{|l|}{ Miscarriages: } \\
\hline Total & $40(14)$ & $37(11)$ & $1.25(0.82$ to 1.91$)$ \\
\hline First trimester & $24(8)$ & $25(7)$ & 1.11 (0.65 to 1.91$)$ \\
\hline Second trimester & $16(5)$ & $12(3.5)$ & 1.55 (0.74 to 3.22$)$ \\
\hline Ectopic pregnancy & $10(3)$ & $1(0.3)$ & 11.60 (1.49 to 90.07$)$ \\
\hline Termination of pregnancy & $47(16)$ & $19(6)$ & 2.87 (1.72 to 4.78$)$ \\
\hline \multicolumn{4}{|l|}{ Blomfield et al $1993^{23}$} \\
\hline \multicolumn{4}{|l|}{ LLETZ: } \\
\hline Second trimester miscarriages & $2 / 40(5)$ & $1 / 80(1)$ & $4.00(0.37$ to 42.80$)$ \\
\hline \multicolumn{4}{|l|}{ Bigrigg et al $1994^{13}$} \\
\hline \multicolumn{4}{|l|}{ LLETZ: } \\
\hline Pregnancy rates & 76/229 (33) & $66 / 229(29)$ & $1.15(0.88$ to 1.51$)$ \\
\hline Time to conception (months): & $\mathrm{n}=72$ & $\mathrm{n}=62$ & \\
\hline $0-3$ & $36(50)$ & $36(58)$ & 0.86 (0.63 to 1.18$)$ \\
\hline $0-6$ & $61(86)$ & $51(82)$ & $1.03(0.89$ to 1.19$)$ \\
\hline $0-12$ & $67(93)$ & $55(89)$ & 1.05 (0.94 to 1.17$)$ \\
\hline$>12$ & $7(10)$ & $12(20)$ & $0.50(0.21$ to 1.20$)$ \\
\hline$>36$ & $4(5.5)$ & $5(8)$ & 0.69 (0.19 to 2.45$)$ \\
\hline Total miscarriages & $5 / 76(7)$ & $6 / 66(9)$ & $0.72(0.23$ to 2.26$)$ \\
\hline Ectopic pregnancy & 2/76 (3) & 2/66 (3) & $0.87(0.13$ to 6.00$)$ \\
\hline \multicolumn{4}{|l|}{ Cruickshank et al $1995^{25}$} \\
\hline
\end{tabular}

LLETZ: 
Table 2 (continued)

\begin{tabular}{|c|c|c|c|}
\hline \multirow[b]{2}{*}{ Treatment and fertility outcomes } & \multicolumn{2}{|c|}{ No with outcome/No in group (\%) } & \multirow[b]{2}{*}{ Relative risk (95\% Cl) } \\
\hline & Treated group & Untreated group & \\
\hline Second trimester miscarriages & $2 / 149(1)$ & $3 / 298(1)$ & $1.33(0.23$ to 7.89$)$ \\
\hline \multicolumn{4}{|l|}{ Sagot et al $1995^{28}$} \\
\hline \multicolumn{4}{|l|}{ Laser conisation: } \\
\hline Miscarriages: & $\mathrm{n}=71$ & $\mathrm{n}=82$ & \\
\hline Total & $10(14)$ & $11(13)$ & 1.05 (0.47 to 2.33$)$ \\
\hline First trimester & $10(14)$ & $11(13)$ & 1.05 (0.47 to 2.33$)$ \\
\hline Second trimester & $0(0)$ & $0(0)$ & $\mathrm{NE}$ \\
\hline Ectopic pregnancy & $2(3)$ & $2(2)$ & $1.15(0.17$ to 7.99$)$ \\
\hline Termination of pregnancy & $6(8.5)$ & $10(12)$ & $0.69(0.27$ to 1.81$)$ \\
\hline \multicolumn{4}{|l|}{ Spitzer et al $1995^{30}$} \\
\hline \multicolumn{4}{|l|}{ Laser conisation, laser ablation: } \\
\hline \multicolumn{4}{|l|}{ Pregnancy rate: } \\
\hline Laser conisation & $67 / 100(67)$ & $28 / 100(28)$ & 2.39 (1.70 to 3.37$)$ \\
\hline Laser ablation & $210 / 333(63)$ & $149 / 333(45)$ & $1.41(1.22$ to 1.63$)$ \\
\hline All laser & $277 / 433(64)$ & $177 / 433(41)$ & 1.56 (1.37 to 1.79$)$ \\
\hline \multicolumn{4}{|l|}{ Total miscarriages: } \\
\hline Laser conisation & $7 / 67(10)$ & $7 / 28(25)$ & $0.42(0.16$ to 1.08$)$ \\
\hline Laser ablation & $24 / 210(11)$ & $26 / 149(17)$ & $0.65(0.39$ to 1.09$)$ \\
\hline All laser & $31 / 277(11)$ & 33/177 (19) & $0.60(0.38$ to 0.94$)$ \\
\hline \multicolumn{4}{|l|}{ Ectopic pregnancy: } \\
\hline Laser conisation & $3 / 67(4.5)$ & 2/28 (7) & 0.63 (0.11 to 3.55$)$ \\
\hline Laser ablation & $5 / 210(2)$ & $2 / 149(1)$ & $1.77(0.35$ to 9.02$)$ \\
\hline All laser & $8 / 277(3)$ & $4 / 177(2)$ & 1.28 (0.39 to 4.18$)$ \\
\hline \multicolumn{4}{|l|}{ Termination of pregnancy: } \\
\hline Laser conisation & $23 / 67(34)$ & $4 / 28(14)$ & $2.40(0.91$ to 6.31$)$ \\
\hline Laser ablation & $52 / 210(25)$ & $24 / 149(16)$ & 1.54 (0.99 to 2.38$)$ \\
\hline All Laser & $75 / 277(27)$ & 28/177 (16) & 1.71 (1.16 to 2.53$)$ \\
\hline \multicolumn{4}{|l|}{ Turlington et al $1996^{32}$} \\
\hline \multicolumn{4}{|l|}{ LLETZ: } \\
\hline Pregnancy rate & $15 / 54(28)$ & $21 / 57(37)$ & $0.75(0.44$ to 1.30$)$ \\
\hline PRIC & $11 / 12(92)$ & $17 / 17(100)$ & $0.95(0.76$ to 1.20$)$ \\
\hline Total miscarriages & $0 / 15(0)$ & $3 / 21(14)$ & $0.20(0.01$ to 3.54$)$ \\
\hline Termination of pregnancy & $0 / 15(0)$ & 2/21 (9.5) & 0.28 (0.01 to 5.35$)$ \\
\hline \multicolumn{4}{|l|}{ Tan et al 2004 } \\
\hline \multicolumn{4}{|l|}{ LLETZ } \\
\hline Total miscarriages & $14 / 119(12)$ & $11 / 119(9)$ & 1.27 (0.60 to 2.69$)$ \\
\hline \multicolumn{4}{|l|}{ Sjoberg et al $2007^{29}$} \\
\hline \multicolumn{4}{|l|}{ laser conisation, LLETZ } \\
\hline Second trimester miscarriages & $7 / 742(1)$ & $0 / 742(0)$ & 15.00 (0.86 to 262.16$)$ \\
\hline \multicolumn{4}{|l|}{ Albrechtsen et al $2008^{4}$} \\
\hline \multicolumn{4}{|c|}{ Cold knife conisation, laser conisation, LLETZ: } \\
\hline Second trimester miscarriages & $226 / 15108(1.5)$ & $8501 / 2164006$ (0.4) (untreated) & 3.81 (3.34 to 4.34 ) (untreated) \\
\hline Second trimester miscarriages & $226 / 15108(1.5)$ & 209/57136 (0.4) (internal) & 4.09 (3.39 to 4.93 ) (internal) \\
\hline \multicolumn{4}{|l|}{ Kalliala et al 2012 } \\
\hline All treatments*: & $\mathrm{n}=6179$ & $n=30463$ & \\
\hline Pregnancy rate & $2578(42)$ & $11642(38)$ & 1.09 (1.06 to 1.13$)$ \\
\hline Total miscarriages & $159(3)$ & $707(2)$ & $1.11(0.93$ to 1.31$)$ \\
\hline
\end{tabular}


Table 2 (continued)

\begin{tabular}{|c|c|c|c|}
\hline \multirow[b]{2}{*}{ Treatment and fertility outcomes } & \multicolumn{2}{|c|}{ No with outcome/No in group (\%) } & \multirow[b]{2}{*}{ Relative risk $(95 \% \mathrm{Cl})$} \\
\hline & Treated group & Untreated group & \\
\hline Ectopic pregnancy & $89(1)$ & $229(1)$ & 1.91 (1.50 to 2.44$)$ \\
\hline Molar pregnancy & $50(1)$ & $225(1)$ & $1.10(0.81$ to 1.49$)$ \\
\hline Termination of pregnancy & $695(11)$ & $2245(7)$ & 1.52 (1.41 to 1.65$)$ \\
\hline \multicolumn{4}{|l|}{ Frega et al $2013^{26}$} \\
\hline \multicolumn{4}{|l|}{ LLETZ: } \\
\hline Total miscarriages & $69 / 475(14.5)$ & $62 / 441(14)$ & 1.03 (0.75 to 1.42$)$ \\
\hline \multicolumn{4}{|l|}{ Spracklen et al 2013 ${ }^{16}$} \\
\hline \multicolumn{4}{|l|}{ All treatments*: } \\
\hline \multicolumn{4}{|l|}{ Time to conception (months): } \\
\hline$>12$ & $25 / 152(16)$ & Untreated 86/1021 (8) & 1.95 (1.29 to 2.95$)$ \\
\hline$>12$ & 25/152 (16) & Colposcopy only 13/151 (9) & 1.91 (1.02 to 3.59$)$ \\
\hline \multicolumn{4}{|l|}{ All treatments ${ }^{*} \mathrm{~T}$} \\
\hline All excisional & $15 / 91(16.5)$ & $51 / 611(8)$ & $1.97(1.16$ to 3.36$)$ \\
\hline All ablative & $10 / 61(16)$ & $35 / 410(8.5)$ & $1.92(1.00$ to 3.68$)$ \\
\hline LLETZ & $8 / 45(18)$ & 25/302 (8) & 2.15 (1.03 to 4.47$)$ \\
\hline Cold knife conisation & $7 / 46(15)$ & 26/309 (8) & 1.81 (0.83 to 3.93$)$ \\
\hline Cryotherapy & $6 / 44(14)$ & 25/295 (8.5) & $1.61(0.70$ to 3.70$)$ \\
\hline Laser ablation & 4/17 (23.5) & 10/115 (9) & $2.71(0.95$ to 7.67$)$ \\
\hline
\end{tabular}

LLETZ=large loop excision of the transformation zone; $\mathrm{NA}=$ not available; $\mathrm{NE}=$ not estimable; NPIC=number of pregnancies in women with intention to conceive; $P R I C=$ pregnancy rates in women with an intention to conceive.

*LLETZ, cold knife conisation, cryotherapy, laser conisation, and laser ablation.

†Compared with untreated women. 


\begin{tabular}{|c|c|c|c|c|c|c|c|}
\hline \multirow{2}{*}{$\begin{array}{l}\text { Fertility outcomes and } \\
\text { treatment }\end{array}$} & \multirow[b]{2}{*}{ Untreated group } & \multirow{2}{*}{$\begin{array}{l}\text { No of } \\
\text { studies }\end{array}$} & \multirow{2}{*}{$\begin{array}{c}\text { No of } \\
\text { women }\end{array}$} & \multicolumn{2}{|c|}{ No with outcome/No in group (\%) } & \multirow{2}{*}{$\begin{array}{l}\text { Effect estimate relative } \\
\text { risk }(95 \% \mathrm{Cl})\end{array}$} & \multirow{2}{*}{$\begin{array}{c}\text { Heterogeneity, P } \\
\text { value }\left(\mathrm{I}^{2} \%\right)\end{array}$} \\
\hline & & & & Treated group & Untreated group & & \\
\hline \multicolumn{8}{|l|}{ Total pregnancy rate } \\
\hline LLETZ & No treatment & 2 & 569 & $91 / 283(32.2)$ & $87 / 286(30.4)$ & $1.00(0.67$ to 1.48$)$ & $0.18(45)$ \\
\hline Laser conisation & No treatment & 1 & 200 & $67 / 100(67.0)$ & $28 / 100(28.0)$ & 2.39 (1.70 to 3.37$)$ & $\mathrm{NE}(\mathrm{NE})$ \\
\hline Laser ablation & No treatment & 1 & 666 & $210 / 333(63.0)$ & $149 / 333(44.7)$ & 1.41 (1.22 to 1.63$)$ & $\mathrm{NE}(\mathrm{NE})$ \\
\hline Treatment NS & No treatment & 1 & 36615 & $2578 / 6179(41.7)$ & $11642 / 30436(38.3)$ & $1.09(1.02$ to 1.64$)$ & $\mathrm{NE}(\mathrm{NE})$ \\
\hline All treatment types & No treatment & 4 & 38050 & $2946 / 6895$ (42.7) & 11 906/31 155 (38.2) & 1.29 (1.02 to 1.64$)$ & $<0.0001(88)$ \\
\hline \multicolumn{8}{|c|}{ Pregnancy rate in women with intention to conceive } \\
\hline All treatment types & No treatment & 2 & 70 & 29/33 (87.9) & $35 / 37(94.6)$ & $0.93(0.80$ to 1.08$)$ & $0.77(0)$ \\
\hline \multicolumn{8}{|l|}{$\begin{array}{l}\text { Time to conception } \\
\text { (months): }\end{array}$} \\
\hline $0-3$ & No treatment & 2 & 175 & 46/93 (49.5) & $45 / 82(54.9)$ & 0.89 (0.67 to 1.19$)$ & $0.58(0)$ \\
\hline $0-6$ & No treatment & 2 & 175 & 73/93(78.5) & $62 / 82(75.6)$ & $1.03(0.89$ to 1.19$)$ & $0.97(0)$ \\
\hline $0-9$ & No treatment & 1 & 41 & $14 / 21(66.7)$ & $13 / 20(65.0)$ & $1.03(0.66$ to 1.59$)$ & $\mathrm{NE}(\mathrm{NE})$ \\
\hline $0-12$ & No treatment & 2 & 175 & $81 / 93(87.1)$ & $69 / 82(84.1)$ & $1.04(0.94$ to 1.16$)$ & $0.62(0)$ \\
\hline $0-24$ & No treatment & 1 & 41 & 18/21 (85.7) & $18 / 20(90.0)$ & 0.95 (0.76 to 1.20$)$ & NE (NE) \\
\hline \multicolumn{8}{|l|}{ Conception >12 months: } \\
\hline Cold knife conisation & No treatment & 2 & 396 & $11 / 67(16.4)$ & $30 / 329(9.1)$ & 1.51 (0.78 to 2.92$)$ & $0.39(0)$ \\
\hline LLETZ & No treatment & 2 & 481 & $15 / 117(12.8)$ & $37 / 36410.2)$ & $1.06(0.25$ to 4.47$)$ & $0.01(84)$ \\
\hline Laser ablation & No treatment & 1 & 132 & $4 / 17(23.5)$ & $10 / 115(8.7)$ & $2.71(0.95$ to 7.67$)$ & $\mathrm{NE}(\mathrm{NE})$ \\
\hline Cryotherapy & No treatment & 1 & 339 & $6 / 44(13.6)$ & 25/295 (8.5) & $1.61(0.70$ to 3.70$)$ & $\mathrm{NE}(\mathrm{NE})$ \\
\hline Excisional treatment & No treatment & 3 & 877 & $26 / 184(14.1)$ & $67 / 693(9.7)$ & 1.03 (0.40 to 2.65$)$ & $0.03(73)$ \\
\hline Ablative treatment & No treatment & 1 & 471 & $10 / 61(16.4)$ & $35 / 410(8.5)$ & $1.92(1.00$ to 3.68$)$ & $\mathrm{NE}(\mathrm{NE})$ \\
\hline All treatment types & No treatment & 3 & 1348 & $36 / 245(14.7)$ & $102 / 1103(9.2)$ & 1.45 (0.89 to 2.37 ) & $0.10(46)$ \\
\hline \multicolumn{8}{|l|}{ Conception >12 months: } \\
\hline Cold knife conisation & Colposcopy only & 1 & 91 & $7 / 46(15.2)$ & $4 / 45(8.9)$ & $1.71(0.54$ to 5.45$)$ & NE (NE) \\
\hline LLETZ & Colposcopy only & 1 & 90 & $8 / 45(17.8)$ & 4/45 (8.9) & 2.00 (0.65 to 6.17$)$ & NE (NE) \\
\hline Laser ablation & Colposcopy only & 1 & 34 & $4 / 17(23.5)$ & $1 / 17(5.9)$ & $4.00(0.50$ to 32.20$)$ & $\mathrm{NE}(\mathrm{NE})$ \\
\hline Cryotherapy & Colposcopy only & 1 & 88 & $6 / 44(13.6)$ & $4 / 44(9.1)$ & $1.50(0.45$ to 4.95$)$ & $\mathrm{NE}(\mathrm{NE})$ \\
\hline Excisional treatment & Colposcopy only & 1 & 181 & $15 / 91(16.5)$ & $8 / 90(8.9)$ & 1.85 (0.83 to 4.16$)$ & $\mathrm{NE}(\mathrm{NE})$ \\
\hline Ablative treatment & Colposcopy only & 1 & 122 & $10 / 61(16.4)$ & $5 / 61(8.2)$ & 2.00 (0.73 to 5.51$)$ & $\mathrm{NE}(\mathrm{NE})$ \\
\hline All treatment types & Colposcopy only & 1 & 303 & 25/152 (16.4) & 13/151 (8.6) & 1.88 (0.99 to 3.55$)$ & $0.88(0)$ \\
\hline \multicolumn{8}{|l|}{ Conception >36 months: } \\
\hline All treatment types & No treatment & 1 & 134 & 4/72 (5.5) & $5 / 62(8.0)$ & 0.69 (0.19 to 2.45$)$ & $\mathrm{NE}(\mathrm{NE})$ \\
\hline
\end{tabular}

LLETZ=Large Loop Excision of the Transformation Zone; NS=not specified; NE=not estimable.

Not all abbreviations mentioned NE to termination of pregnancy. 
Table 4| Meta-analysis of studies comparing early pregnancy outcomes in women after treatment for cervical intraepithelial neoplasia versus untreated controls

\begin{tabular}{|c|c|c|c|c|c|c|}
\hline \multirow[b]{2}{*}{$\begin{array}{l}\text { Early pregnancy outcomes by } \\
\text { treatment group }\end{array}$} & \multirow{2}{*}{$\begin{array}{l}\text { Untreated } \\
\text { group: No } \\
\text { of studies }\end{array}$} & \multirow{2}{*}{ No of women } & \multicolumn{2}{|c|}{ No with outcome/No in group (\%) } & \multirow[b]{2}{*}{$\begin{array}{l}\text { Effect estimate relative risk } \\
\qquad(95 \% \mathrm{Cl})\end{array}$} & \multirow[b]{2}{*}{$\begin{array}{l}\text { Heterogeneity: P } \\
\text { value }\left(I^{2} \%\right)\end{array}$} \\
\hline & & & Treated group & Untreated group & & \\
\hline \multicolumn{7}{|l|}{ Miscarriage rates } \\
\hline \multicolumn{7}{|l|}{ Total miscarriages: } \\
\hline Cold knife conisation & 3 & 950 & $62 / 448(13.8)$ & $53 / 502(10.6)$ & $1.30(0.92$ to 1.83$)$ & $0.84(0)$ \\
\hline LLETZ & 4 & 1332 & $88 / 685(12.8)$ & $82 / 647(12.7)$ & $1.03(0.77$ to 1.36$)$ & $0.58(0)$ \\
\hline Laser conisation & 2 & 248 & $17 / 138(12.3)$ & $18 / 110(16.4)$ & $0.69(0.28$ to 1.69$)$ & $0.14(53)$ \\
\hline Laser ablation & 1 & 359 & $24 / 210(11.4)$ & $26 / 149(17.4)$ & 0.65 (0.39 to 1.09$)$ & $\mathrm{NE}(\mathrm{NE})$ \\
\hline Excisional treatment & 9 & 2530 & $167 / 1271(13.1)$ & $153 / 1259(12.2)$ & 1.07 (0.87 to 1.31$)$ & $0.50(0)$ \\
\hline Ablative treatment & 1 & 359 & $24 / 210(11.4)$ & $26 / 149(17.4)$ & 0.65 (0.39 to 1.09$)$ & NE (NE) \\
\hline Treatment NS & 1 & 36615 & $159 / 6179(2.6)$ & $707 / 30436(2.3)$ & $1.11(0.93$ to 1.31$)$ & NE (NE) \\
\hline All treatment types & 10 & 39504 & $350 / 7660(4.6)$ & $886 / 31844(2.8)$ & $1.04(0.90$ to 1.21$)$ & $0.36(9)$ \\
\hline \multicolumn{7}{|l|}{ First trimester miscarriages: } \\
\hline Cold knife conisation & 3 & 950 & $41 / 448(9.2)$ & $38 / 502(7.6)$ & $1.20(0.78$ to 1.83$)$ & $0.91(0)$ \\
\hline Laser conisation & 1 & 153 & 10/71 (14.1) & 11/82 (13.4) & 1.05 (0.47 to 2.33$)$ & $\mathrm{NE}(\mathrm{NE})$ \\
\hline Excisional treatment & 4 & 1103 & $51 / 519(9.8)$ & $49 / 584(8.4)$ & $1.16(0.80$ to 1.69$)$ & $0.97(0)$ \\
\hline \multicolumn{7}{|l|}{ Second trimester miscarriages: } \\
\hline Cold knife conisation & 3 & 950 & $21 / 448(4.7)$ & 15/502 (3.0) & 1.55 (0.79 to 3.01$)$ & $0.58(0)$ \\
\hline LLETZ & 2 & 567 & $4 / 189(2.1)$ & $4 / 378(1.1)$ & $1.98(0.48$ to 8.21$)$ & $0.47(0)$ \\
\hline Laser conisation & 1 & 153 & $0 / 71(0)$ & $0 / 82(0)$ & $\mathrm{NE}$ & NE (NE) \\
\hline Excisional treatment NS & 2 & 2180598 & $233 / 15850(1.5)$ & $8510 / 2164748(0.4)$ & 3.82 (3.35 to 4.35$)$ & $0.34(0)$ \\
\hline Excisional treatment & 8 & 2182268 & $258 / 16558(1.6)$ & $8520 / 2165710(0.4)$ & 2.60 (1.45 to 4.67$)$ & $0.12(41)$ \\
\hline \multicolumn{7}{|l|}{ Ectopic pregnancy } \\
\hline Cold knife conisation & 2 & 388 & 13/282 (3.4) & $2 / 447(0.4)$ & 6.83 (1.50 to 31.02$)$ & $0.44(0)$ \\
\hline LLETZ & 1 & 142 & $2 / 76(2.6)$ & $2 / 66$ (3.0) & 0.87 (0.13 to 6.00$)$ & NE (NE) \\
\hline Laser conisation & 2 & 248 & $5 / 138(3.6)$ & $4 / 110(3.6)$ & $0.82(0.23$ to 2.99$)$ & $0.64(0)$ \\
\hline Laser ablation & 1 & 359 & $5 / 210(2.4)$ & 2/149 (1.3) & 1.77 (0.35 to 9.02$)$ & $\mathrm{NE}(\mathrm{NE})$ \\
\hline Excisional treatment & 5 & 1219 & $20 / 596$ (3.4) & $8 / 623(1.3)$ & $1.77(0.59$ to 5.27$)$ & $0.19(35)$ \\
\hline Ablative treatment & 1 & 359 & $5 / 210(2.4)$ & $2 / 149(1.3)$ & 1.77 (0.35 to 9.02$)$ & NE (NE) \\
\hline Treatment NS & 1 & 36615 & 89/6179 (1.4) & $229 / 30436(0.8)$ & 1.91 (1.50 to 2.44$)$ & $\mathrm{NE}(\mathrm{NE})$ \\
\hline All treatment types & 6 & 38193 & $114 / 6985(1.6)$ & 239/31 $208(0.8)$ & 1.89 (1.50 to 2.39 ) & $0.44(0)$ \\
\hline \multicolumn{7}{|l|}{ Molar pregnancy } \\
\hline Cold knife conisation & 1 & 194 & $0 / 88(0)$ & $1 / 106(0.9)$ & $0.40(0.02$ to 9.88$)$ & $\mathrm{NE}(\mathrm{NE})$ \\
\hline Treatment NS & 1 & 36615 & $50 / 6179(0.8)$ & $225 / 30436(0.7)$ & $1.10(0.81$ to 1.49$)$ & NE (NE) \\
\hline All treatment types & 2 & 36809 & $50 / 6267(0.8)$ & $226 / 30542(0.7)$ & $1.08(0.80$ to 1.47$)$ & $0.54(0)$ \\
\hline \multicolumn{7}{|l|}{ Termination of pregnancy } \\
\hline Cold knife conisation & 3 & 950 & $76 / 448(17.0)$ & $35 / 502(7.0)$ & 2.45 (1.68 to 3.58$)$ & $0.53(0)$ \\
\hline LLETZ & 1 & 36 & $0 / 15(0)$ & $2 / 21(9.5)$ & 0.28 (0.01 to 5.35$)$ & $\mathrm{NE}$ (NE) \\
\hline Laser conisation & 2 & 248 & 29/138 (21.0) & $14 / 110(12.7)$ & $1.29(0.38$ to 4.37$)$ & $0.07(69)$ \\
\hline Excisional treatment & 6 & 1234 & $105 / 601(17.5)$ & $51 / 633(8.1)$ & $1.87(1.12$ to 3.11$)$ & $0.11(44)$ \\
\hline Laser ablation & 1 & 359 & $52 / 210(24.8)$ & $24 / 149(16.1)$ & 1.54 (0.99 to 2.38$)$ & $\mathrm{NE}(\mathrm{NE})$ \\
\hline Ablative treatment & 1 & 359 & $52 / 210(24.8)$ & $24 / 149(16.1)$ & 1.54 (0.99 to 2.38$)$ & $\mathrm{NE}(\mathrm{NE})$ \\
\hline Treatment NS & 1 & 36615 & $695 / 6179(11.2)$ & $2245 / 30436(7.4)$ & $1.52(1.41$ to 1.65$)$ & $\mathrm{NE}(\mathrm{NE})$ \\
\hline All treatment types & 7 & 38208 & $852 / 6990$ (12.2) & $2320 / 31218(7.4)$ & 1.71 (1.31 to 2.22$)$ & $0.10(41)$ \\
\hline
\end{tabular}

LLETZ=large loop excision of the transformation zone; NS=not specified; NE=not estimable. 


\section{Figures}

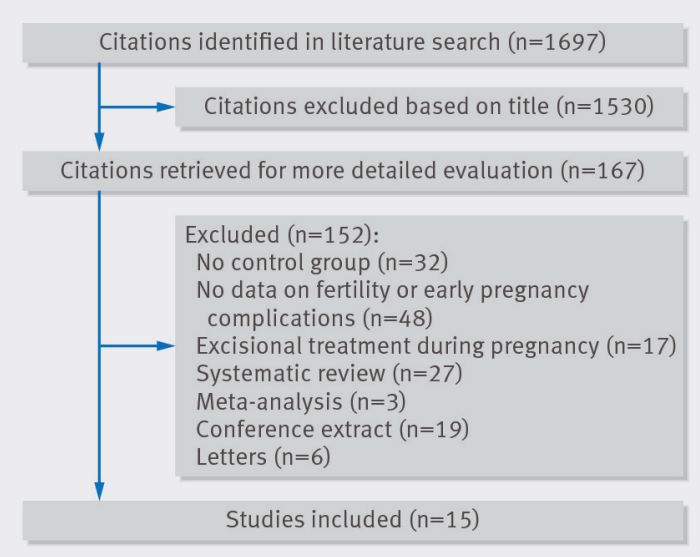

Fig 1 PRISMA flowchart

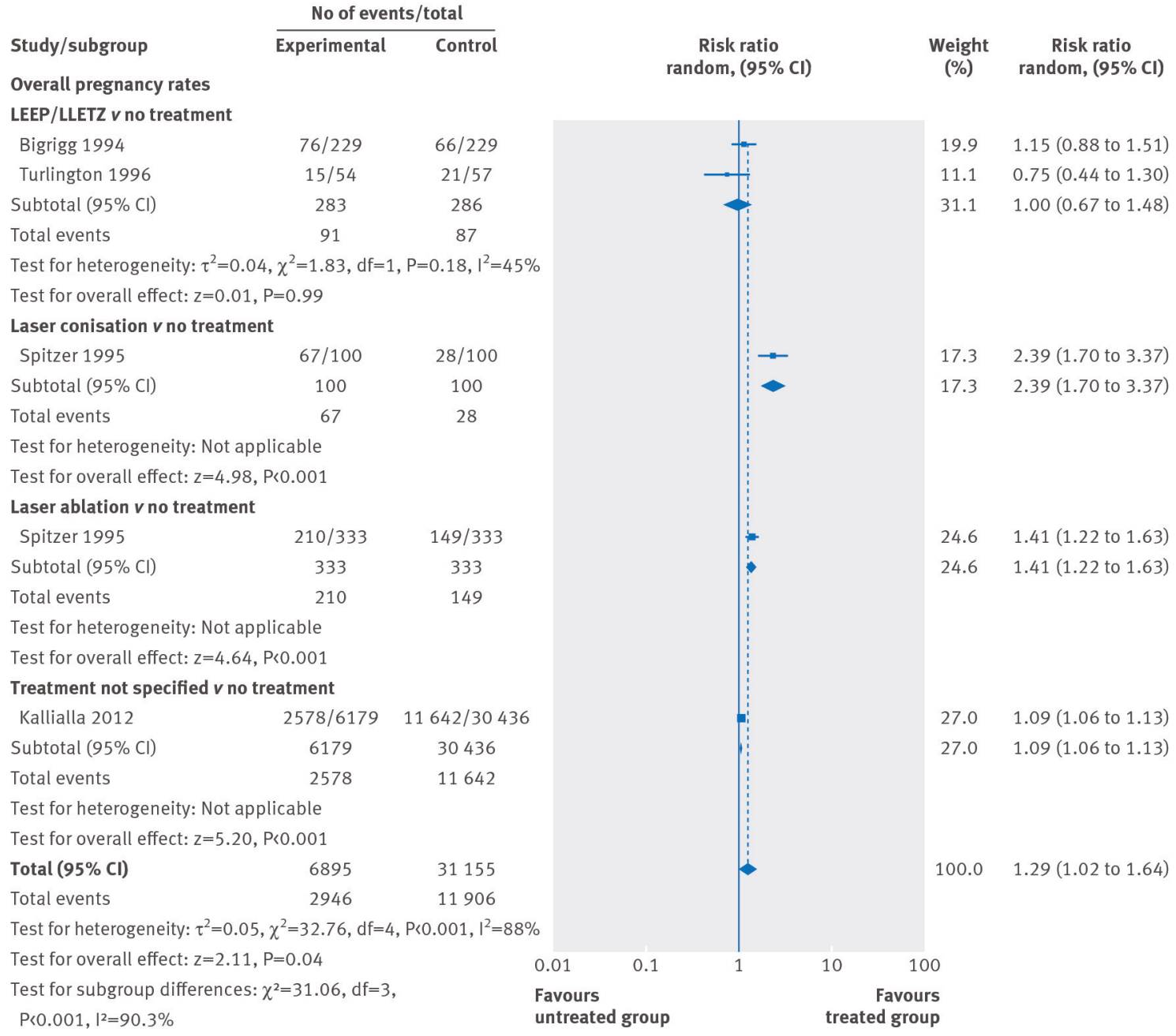

Fig 2 Meta-analysis on overall pregnancy rates in treated versus untreated women. LLETZ=large loop excision of the transformation zone; LEEP=loop electrosurgical excisional procedure 


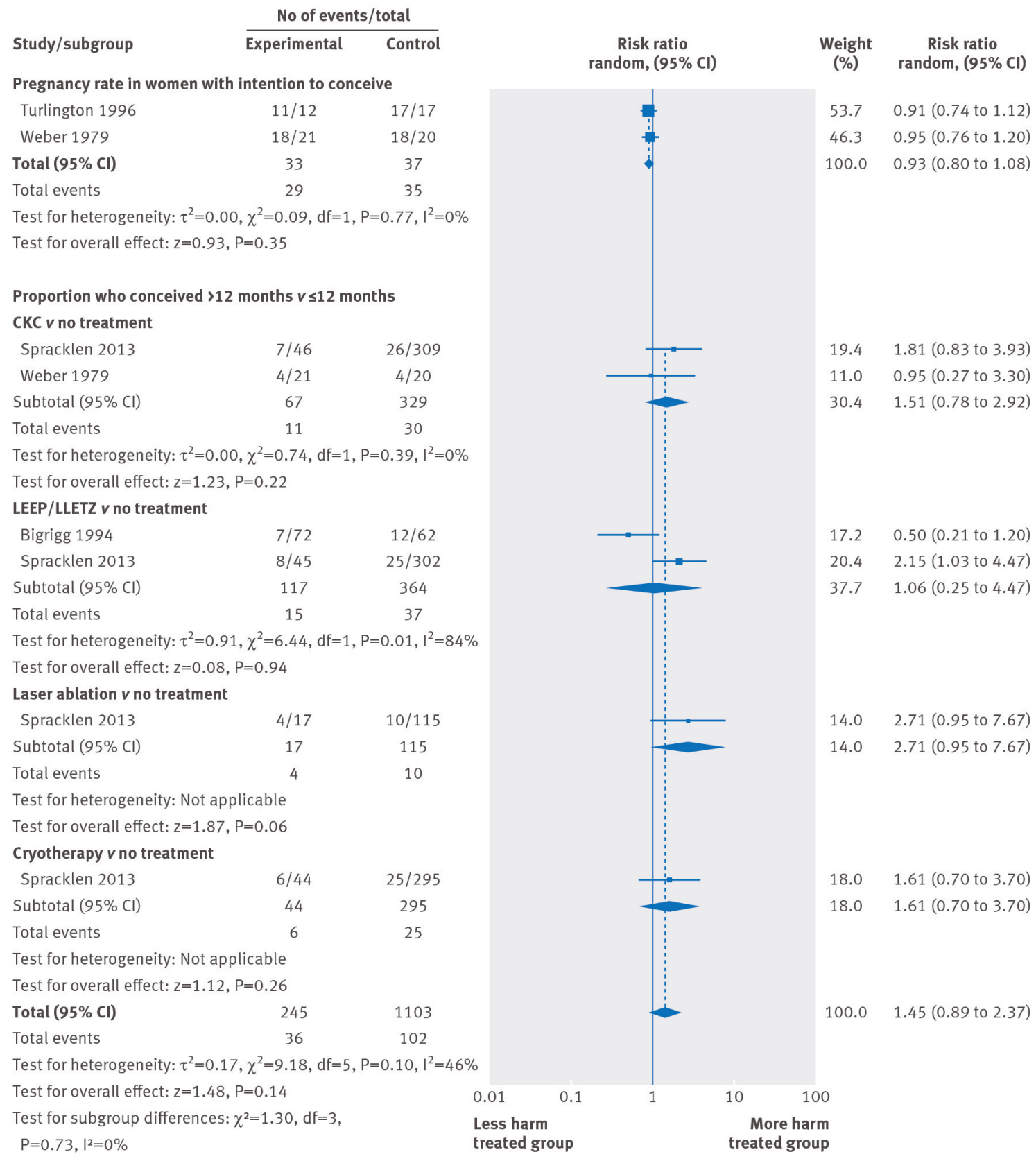

Fig 3 Meta-analysis on pregnancy rates in women with an intention to conceive, and time to conception greater than 12 months in treated versus untreated women. $C K C=$ cold knife conisation; LLETZ=large loop excision of the transformation zone; LEEP=loop electrosurgical excisional procedure 


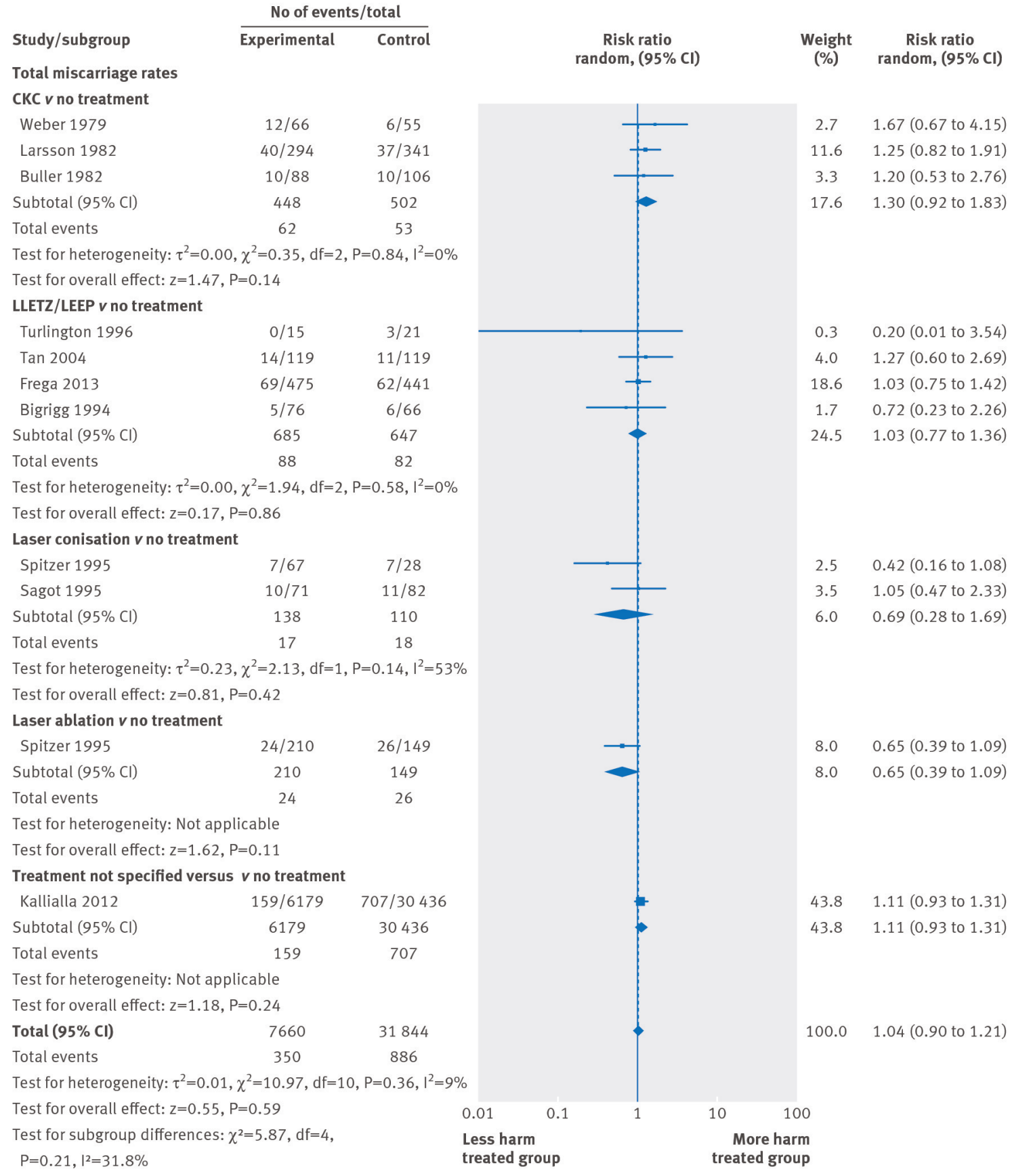

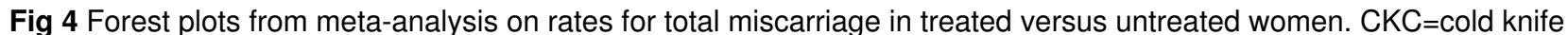
conisation; LLETZ=large loop excision of the transformation zone; LEEP=loop electrosurgical excisional procedure 


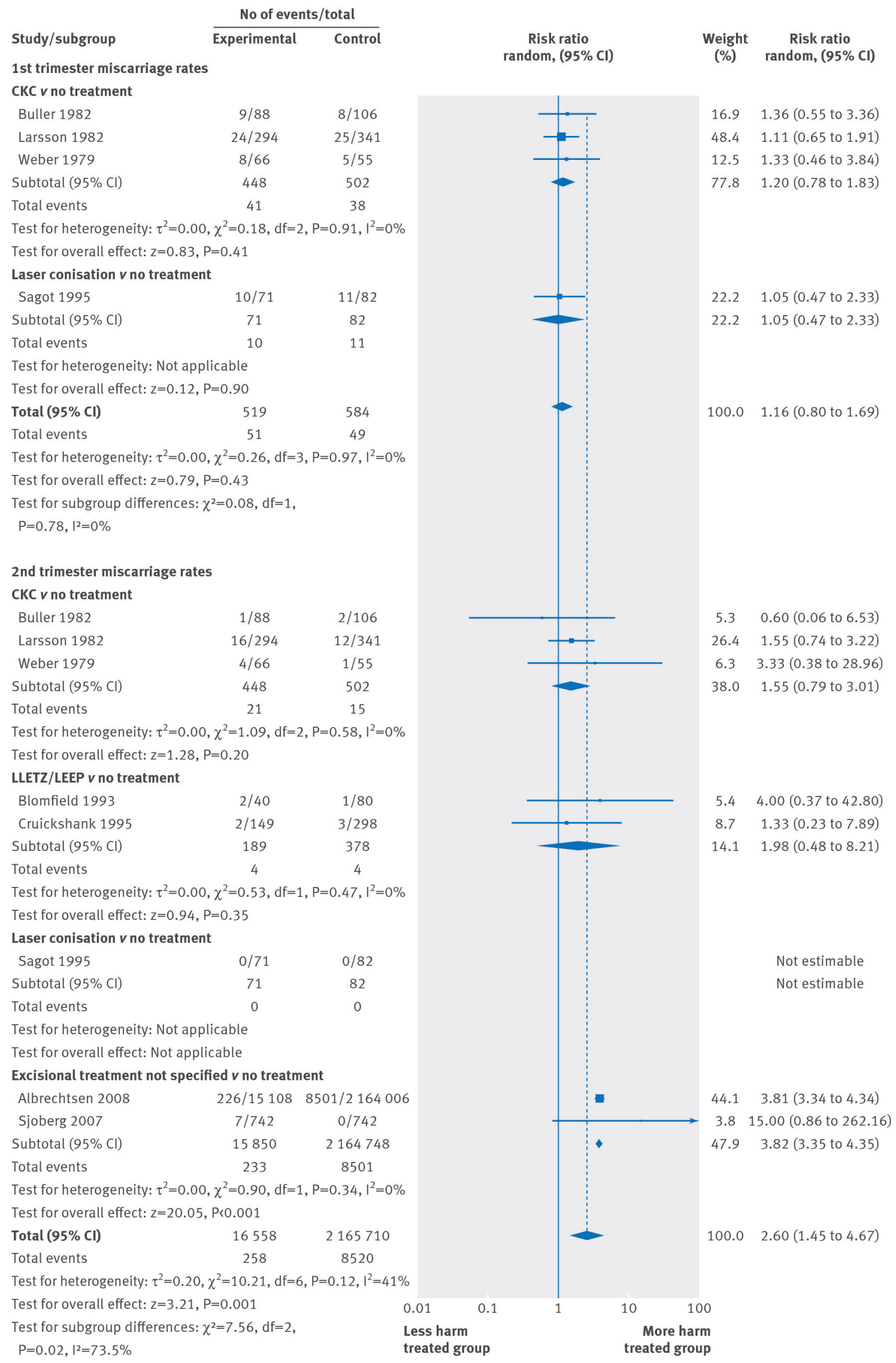

Fig 5 Forest plots from the meta-analysis on rates for miscarriage in first and second trimesters in treated versus untreated women. $\mathrm{CKC}=$ cold knife conisation; LLETZ=large loop excision of the transformation zone; LEEP=loop electrosurgical excisional procedure 